Erratum

\title{
Tectonic significance of the Taitung Canyon, Huatung Basin, east of Taiwan
}

\author{
Jean-Claude Sibuet ${ }^{1 *}$, Shu-Kun $\mathrm{Hsu}^{2}$ and Alain Normand ${ }^{1}$ \\ ${ }^{1}$ Ifremer Centre de Brest, B.P. 70, 29280 Plouzané Cedex, France \\ ${ }^{2}$ Institute of Geophysics, National Central University, Chung-Li, Taiwan 32054 \\ *Corresponding author (E-mails: jcsibuet@ifremer.fr; hsu@oc.gep.ncu.edu.tw; alain.normand@ifremer.fr)
}

Marine Geophysical Researches (2004) 25: 95-107

DOI 10.1007/s11001-005-0736-2

The second part of Figure 6 was missing in the original. The complete Figure 6 is shown on the following pages. 


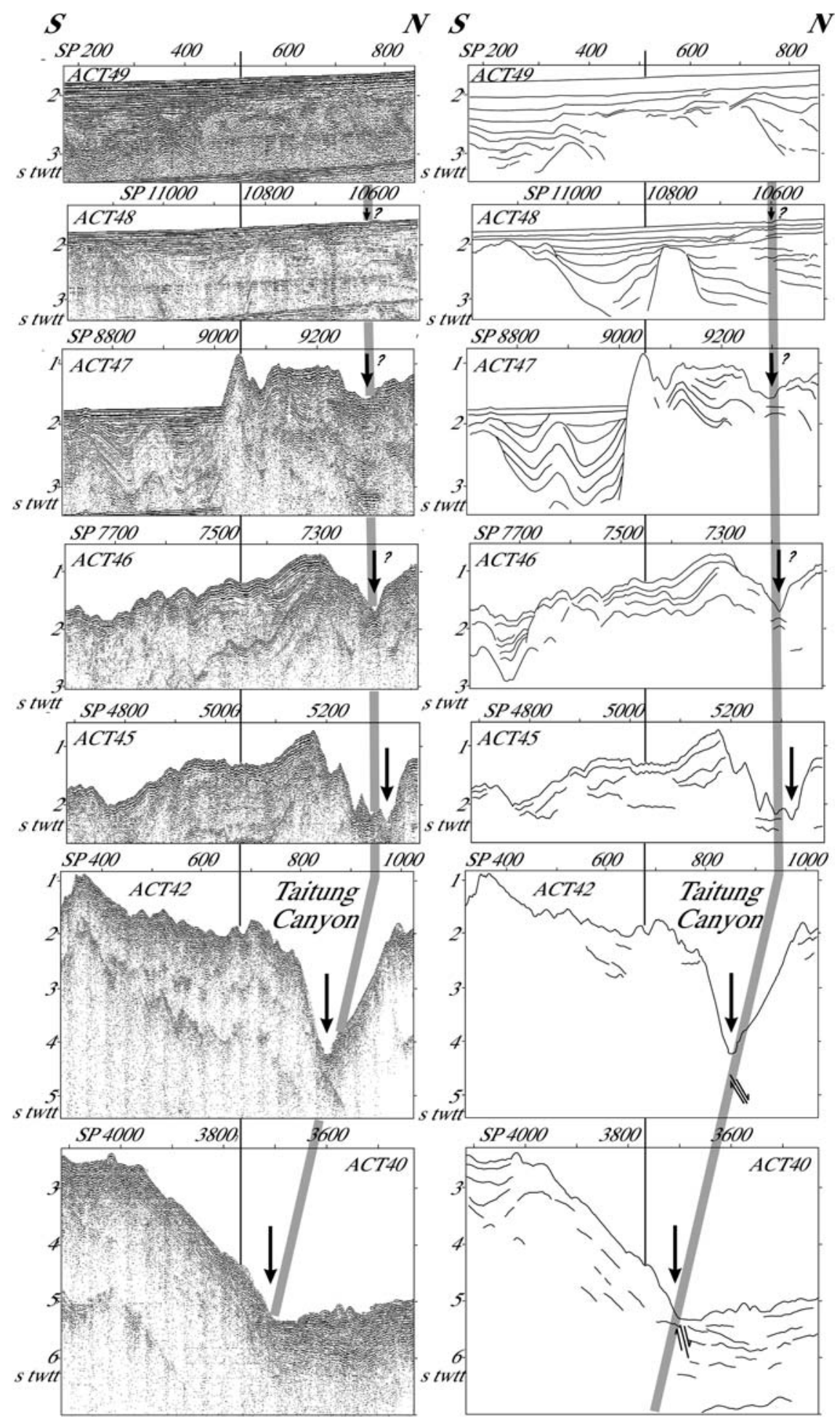

Figure 6. Time migrated seismic reflection profiles located in Figure 5b and aligned on the straight line B' (located in Figure 5b). Vertical exaggeration: 13. Interpretation of the 12 ACT seismic reflection profiles on the right-hand side. Normal faults are identified on ACT profiles 42-85. SP, shot point; s twtt, second two-way travel time. 


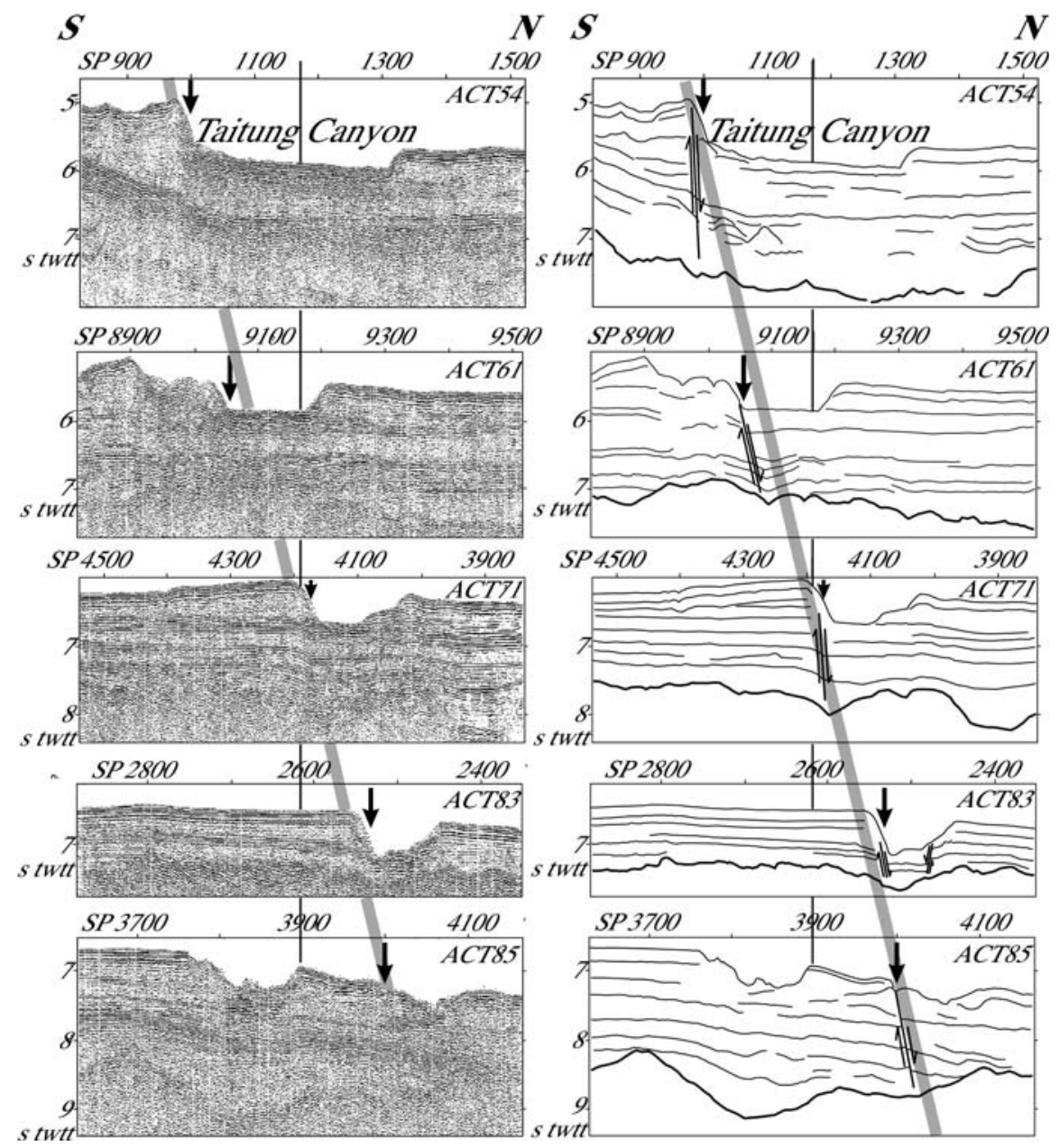

Figure 6. Continued 